sufficient indication, because in many instances a relapse occurs between five and eight years.

In widely extended disease the tumour must be treated in two or more sections at intervals of six to eight weeks, and one of the most important effects I have noted is the great improvement in the condition of the patient which follows oven the first application. This indeed is sometimes so marked as to be a disadvantage, in that the patients either return to work and so damage the skin overlying the port of entry, which is not so healthy as the surrounding integument, or else fancy themselves cured and fail to return at the appointed date, so that it is only months later, when the disease is often out of hand, that they come back expecting once more-often in vain-the relief they obtained from the first application. Again, not only is there almost entire absence of disability following irradiation, but in most cases where the relief is only temporary - as is also of ten the case after surgical procedures-the period of improvement is in nearly all instances longer than the surgeon could have given, and that without the considerable discomfort of an operation.

\section{Classification of Results.}

Results should be classified according to the method employed.

1. Roentgen Therapy alone.-As it is only within the last eighteen months to two years that this method has been successfully employed it is too early to speak of results, which, however, lose nothing by comparison with combined Roentgen and radium therapy data, and there is the added gain that with correct technique there is practically no risk of burning the patient.

2. Roentgen Therapy together with Radium.-In Germany the practice is to follow up the radium with Roentgen therapy. Two cases, treated in 1916, were seen in Erlangen; they were both peasant women, and looked as if they had never been ill in their lives. Two other cases seen in Munich, treated at a sligbtly shorter interval, were equally well. In Stockholm Professor Forsseli reserves radium to administer the coup de grâce following any exhibition of Roentgen rays.

3 (a). Roentgen Therapy with Copper Electrolysis.-This is proving the most satisfactory method of approach. There are some added dangers' of burning the bowel owing to copper particles being excreted there; but the added benefits to the patient outweigh any disadrantages from this. It seems almost impossible to explain the reason for the great improvement in the condition of the patient, but there is no doubt about it. There is another advantage in that the scar resulting from this form of treatment is loose and supple, and in fungating conditions suppuration is lessened. 'This form of treatment is spocially effective in malignant skin lesions which have resisted other forms of treatment, even including the application of radium.

One case I saw of a middle-aged man who had ha l an extensive ulcerative epitheliomatous growth of the skin overlying one scapula. He received the usual dose of $x$ rays, which bad not the slightest effect. After a period of eight weeks he was treated by copper ionization and again irradiated. Withiu a very short time copper ionization and again irradiated. Withiu a very short time an appreciable difference was noticeable, and the ulcerated area further eight weeks and again after ten weeks. Within three months of the second treatment the lesion was healed and had remained so when seen two years later. Within the last few months, however, a recurrence took place in the middle of the scar, but this has been successfully treated again.

3 (b). Roentgen Therapy and Packing with Paraffin Blocks.-I was not able to see any results from this or even the apparatus in use, as the Surgical Clinic Roentgen Department was being rebuilt at the time of my visit; but despite its originator's claim and satisfaction, I think that a longer period than twelve months ought to elapse before any definite pronouncements can be made; but should it be successfal it will lead to a very great simplification in the technique employed.

It is necessary to impress on workers the dangers as well as the benefits contingent upon the use of these newer methods. With the older methods there was very little if any danger of irritating a growtl, but a carelessly focused application of the intensive rays may so stimulate an outlying portigen of the growth that the patient, soon succumbs to this rapidly growing portion.

Furthermore, the old days of haphazard application are gone-I hope for ever. It is no longer sufficient for the patient to come with a rough diagnosis and receive treat ment ; it is necéssary that he should undergo an extensive clinical, laboratory, and if necessary radiological examination -first, to ascertain the exact situation and extent, so far as is possible, of the tumour; and secondly, the condition of the patient and his fitness to undergo treatment. One of the most important examinations is that of the blood, which serves as the principal indicator of the state of the patient's health, and unless or until this conforms to a certain definite standard treatment cannot be safely undertaken.

The secret of success by these methods is intimate co. operation between clinician, pathologist, physicist, and radio. logist ; this necessarily means that it is a method which can and should be employed only in large hospitals where this co-operation can be easily obtained. The ideal is that there sliould be one laige central institute in each of the greater cities where these conditions obtain.

Nothing could be worse thin the action of some of the smaller hospitals-probably assured by those who do not know that there is no danger attending upon the use of this apparatus-in installing an intensive high-tension outfit, the working of which is positively dangerous in untrained hands. The technique should be employed only when a competent, properly qualified, and trained radiologist can be in attendance the whole time. It is absolutely essential that the greatest care shouid be taken that the rays are accurately focused, and this entails an accurate knowledge of anatomical relations that cannot be expected of even the best sister or lay assistant. This alone means that this technique should be on no account employed in cottage or even the smaller town hospitals, but only in central institutes in larger towns, as in the former case the radiologist at the best can be only a part-time officer, while the treatment, if justice is to be done it, must have at least one whole-time officer, who must not only personally make every focusing, but inust also observe the patient from time to time in order to see that the rays are reaching the desired spot. Apart from the saving in capital outlay, by preventing unnecessary and wasteful duplication of apparatus, the prevention of the tremendous wastage of human life and happiness which would ensue through the inefficient and incorrect treatment that would necessarily obtain at the small local hospitals, is alone an overwhelming argument in favour of the large central institute, where the large number of cases seen and treated. together with the trained staff and opportunities for research and co-operation, conduce to a very much better end-result.

There cannot be the slightest doubt that intensive therrapy is a great improvement on older methods, nor that it has come to stay; but it must be remembered, above all, that good and lasting results are only to be obtained by constant care and unremitting attention to detail. It is to be hoped, now that deep therapy is an establisled fact, that any impróvements which follow will come rapidly and be along lines which will allow considerable simplification of detail. . It is to be feared, however, that much of the deep therapy apparatus that is being installed in this country will not be properly used and that much discredit will fall on a method that is of very great help in relieving, if not in curing, tho dread scourge of cancer.

Seitz und Wintz, p. 7 et seq.

Grosamann, Fortschritie a. d. Geb. d. Roentgsnstr., Bd. 22

Vil. Szilard, Strahlentherapie, Bd. 5.

\section{THE RESULTS OF TREATMENT IN SYPHILIS} OF THE CENTRAL NERVOUS SYS'TEM.

\author{
BY
}

REGINALD HEARN, M.A., M.D.CANTAB.

CLINICAL ASSISTANT TO THE LONDON LOCK HOSPITAL AND TO THE WEST END HOSPITAL FOR NERTOUS DISEABES.

The following paper is a review of one hundred cases of syphilis of the central nervous system treated at the Liondon Lock Hospital during the last two years. All the patients were men. Many more have been treated, but as a great number of these have been lost sight of, and many have been irregular in their attendance, it has been thought advisable to concentrate on one hundred cases only. Space prevents each case from being reviewed in detail, but it is hoped that the illustrative cases are sufficient to prove the main premisses of the writer. These are as follows:

1. A man is much more likely to develop nervous syphilis if his primary sore is of the papulo-erosive type. "In the 100 cases under review 64 showed no trace of any scai, 33 showed the slight and almost invisible type of scar which 
follows a papulo-erosive chancre when it leaves any scar at all, 2 showed scars typical of a papulo-ulcerative chancre, and in only one case did the scar prove that the original sore was a primary granulating chancre. One may therefore suggest that the smaller and the more transient the original sore the more likely is the patient to develop a nervous manifestation in later years. This no doubt explains why it is that so many patients suffering from obvious nervous syphilis are unable to give any history of an original infection.

2. Seventeen were of the meningeal, interstitial, or late secondary type, and of these two were definite "neuro. recurrences" following salvarsan. In one case a facial paralysis appeared seven weeks after the last injection of neo-salvarsan, and fourteen weeks from the appearance of the sore, the treatment having consisted of 3.6 grams of neosalvarsan administered in six weekly injections of 0.6 gram. The other case is described in detail later. Of the remaining 15 cases 10 had had no treaiment worth mentioning, 3 had been well treated for nearly two years with injections of neosalvarsan and mercury, and 2 had taken mercury internallyin one case for eighteen months and in the other for a year.

As the result of treatment all these patients were restored to normal health, so far as could be determined both by clinical and pathological means. There is, however, one exception to this statement. It was found that patients who complained of tinnitus aurium never lost this distressing symptom. The above good results only occurred provided the special treatment was followed up by an ordinary course of treatment for the syphilis. If this was neglected, the meningeal symptoms tended to recur and the cerebro-spinal fluid to become pathological again.

3. Degenerative or parenchymatous cases were materially benefited by treatment, so far as their subjective symptoms were concerned. Eighty-three cases were treated, but in no instance was it found possible to bring about any alteration in the physical signs, or to effect any permanent improvement in the pathological picture presented by the cerebro-spinal fluid. The question of treating this type of case was decided, not by the patient's physical signs but by his symptoms. If he complained of severe lightning pains, bladder trouble, or any other of the common symptoms of degenerative lesions, such as are met with in tabes or tabo-paresis, then it was found that the special treatment outlined below would almost certainly improve him. But if he complained of nothing, and the condition was discovered during examination, then it was found best to leave him alone.

4. The condition of the cerebro-spinal fluid was found to be of no value in deciding whether a patient suffering from degenerative neuro-syphilis should be treated. Four of the eighty-three cases were clinically typical tabetics, but the cerebro-spinal fluids were normal. All the same their subjective symptoms were greatly improved by treatment. It was found useless to gauge the efficiency of one's treatment by a progressive diminution in the cell count or in a reduction of the positivity of the Wassermann reaction. Broadly speaking, all the tests employed appeared to be uninfluenced by treatment. It is true that in two of the eighty-three cases the cell count came down to single figures, and in one the Wassermann reaction became negative, but this exception is not sufficient justification for assuming that the change wrought was necessarily the result of the treatment. It is too often forgotten that the tabetic lesion tends to come to a standstill, and in such cases the cerebro-spinal fluid may become normal once nore.

5. In contradiction to the generally accepted view, general paretics were improved, and the onset of insanity postponed, provided that they were brought under treatment before they had become obviously stupid and fatuous. When the latter stage was reached treatment was worse than useless and only accelerated the fatal termination. Seven cases were treated in this series, of whom two were already stupid. These latter made no improvement: one is dead and the other in an asylum. But the other five are all holding their own, and three of them are certainly distinctly better. Their cerebro-spinal fluids, however, are just as pathological as on the day when they started treatment, and it may be mentioned in passing that when once the gold sol curve has assumed the paretic form it never changes again.

Rationale and Method of T'reatment.

On the first day on which the patient was seen and a clinical diagnosis of nervous syphilis either made or suspected, the cerebro-spinal fluid was examined so as to correlate the pathological findings with what was noted on ordinary clinical examination. A week later the patient was given a maximum intravenous injection of one of the salvarsan substitutes, and, after a further interval of one week, the injection was repeated and immediately followed by drainage of the thecal canal. This method of alternate weekly injections and injections plus drainage was continued until the patient had received eight injections and four tappings. In addition most patients received one or more intramuscular injections of intramine to intensify the action of the saivarsan substitutes, and to ward off metallic intoxica. tion. The patient was then put on a potassium iodide mix. ture (with mercury as well if the case was "meningeal") and the course repeated in two or three months' time if he felt no better, or if the symptoms returned. Provided that a suitable interval had elapsed since the termination of the last course, it was found that the patient's symptoms were the best indication as to when it was advisable to begin another.

The method outlined abore was used in preference to the intrathecal injection of salvarsanized or mercurialized serum for the following reasons. The treatment adopted is extremely simple, it causes the patient little or no distress, and it can be done with complete safety in the out-patient department or the consulting-room. The patient can get down from the table immediately the drainage is finished, and he is able to go about his ordinary business for the rest of the day. Headache was but rarely met with, and one might add that headache following lumbar puncture was found to be most infrequent when the cerebro-spinal fluid showed evidence of nervous syphilis, whereas it was almost the rule when the fluid was normal.

Recent researches ${ }^{1}$ tend to show that the function of the cerebro-spinal fluid is to drain away rather than to supply, and that its withdrawal by lumbar puncture creates a negative pressure with a resulting ultra-filtration of substances from the blood. If, therefore, a drug is injected intravenously and the thecal canal drained immediately afterwards, the drug should be drawn more rapidly through the choroid plexuses on account of the negative pressure thus set up. Furthermore, if one accepts this view of the function of the cerebro-spinal fluid, the whole rationale of intraspinal medication falls to the ground, and one must conclude that the good results which do undoubtedly sometimes follow intrathecal injections of salvarsanized serum are due not to the injections but simply to the drainage. In this connexion the work of Barbat ${ }^{2}$ is most striking. He showed that in 26 patients who were given an intravenous injection of neoEalvarsan and tapped immediately afterwards, it was possible, after twenty-four hours, to demonstrate 0.025 part of arsenic per 100,000 in the cerebro-spinal fluids of 23 of them. While, on the other hand, Rieger and Solomon ${ }^{3}$ showed that, if three hours were allowed to elapse after the injection, no arssenic could be detected in the cerebro-spinal fluid

We can assume, then, that drugs injected intravenously do reach the cerebro-spinal fluid, provided that the injection is followed immediately by an auxiliary tapping. Finally, this treatment is absolutely harmless, while it was found that intraspinal injections of salvarsanized serum did in a few cases materially aggravate the lesions. It was because of this that Mr. McDonagh introduced the method now used at the Lock hospitals.

\section{Illustrative Cases.} CASE I.

Male, aged 28. This was a true "nearo-recurrence." He developed a papulo-erosive chancre in the coronal sulcus in April 1919, and was treated with nine injections of neo-salvarsan and a course of mercury for three months. In October, 1919, he first noticed headache which was worse at night-this was nearly ten weeks after his last injection of neo-salvarsan. When seen in December, 1919, he complained also of deafuess, tinuitus aurium, and oceasional attacks of giddiness. On examination both the vestibular and cochlear portions of the auditory nerve werefound
to be affected; there was obvious deafness. Furthermore, to be affected; there was obvious deafness. Furthermore, nystagmus was present, and the water and rotary tests for vestibular nerve involvement were positive. His course of treatment extended from December 9th, 1919, to the end of February, 1920. On December 9th an examination of the cerebro-spina tinid gave the following result (a normal result is shown for comparison):

\begin{tabular}{|c|c|c|c|c|c|c|}
\hline Colla & & & & $\begin{array}{l}\text { Patient's } \\
\text { C.-S. F. }\end{array}$ & & $\begin{array}{l}\text { Normat } \\
\text { Resive. } \\
\text { I to } 5\end{array}$ \\
\hline $\begin{array}{l}\text { Cells } \\
\text { Globulin }\end{array}$ & $\bullet$ & $\infty$ & 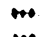 & 120 & ••p & 100 \\
\hline Wasserm & änn & action & $\cdots$ & ++ & & \\
\hline Golỉ sol & $\ldots$ & $\ldots$ & $\ldots$ & 000112353 & $\ldots$ & 000000000 \\
\hline
\end{tabular}

Examination on December 23rd showed : Cells 210, globulin and Wassermann tests positive, gold sol 000112253 . 
From this time onwards the findings became less patbological, and when the cerebro-spinal fluid was examined at the end of February, 1920, it was found to be perfectly normal.

This, of course, was a case of meningitis with involvement of both vestibular and cochlear branches of the auditory nerve. From the first drainage the physical signs improved enormously, and, when examined fourteeu days after the last, the headache, deafness, and nystagmus had entirely disappeared. The tinnitus aurium, however, persisted, as always happens in this type of case. The rise in the cell count after the first tapping is worth noting, as it wis almost a constant phenomenon, especially in cases of meningitis.

\section{Case II.}

A man, aged 34, developed a papulo-erosive chancre on the fraenum in 1917. When seen in February, 1920, he complained of intolerable headache and almost complete loss of memory for recent events. He had had two epileptic fits in the previous month. Clinical examination revealed nothing abnormal except that the deep reflexes were rather exaggerated. His cerebrospinal fluid was examined on February 2nd and 3rd 1920, and again on March 27th, 1921. The results are shown in the following table:

$$
\begin{array}{lccccccc} 
& & \multicolumn{3}{c}{\text { Feb. 2, 1520 }} & \text { Feb. 23, 1920. } & \text { Mar. 27. } 1921 . \\
\text { Oells } & \ldots & \ldots & 100 & \ldots & 154 & \ldots & \ldots \\
\text { Globnlin } \ldots & \ldots & \ldots & + & \ldots & \text { doubtful } & \ldots & - \\
\text { Wassermann } & \ldots & ++ & \ldots & \text { doubtful } & \ldots & - \\
\text { Gold sol } & \ldots & \ldots & 001234444 & \ldots & 011332111 & \ldots & 000000000
\end{array}
$$

Treatment extended from February 2nd to April 27th, 1920. The patient's symptoms rapidly cleared up. He continued on mercury and potassium iodide, and, when seen a year later, looked in robust health. He complained of nothing, and had had no more fits. His cerebro-spinal fluid was again examined and, as will be seen by the table, was found to be perfectly normal.

CASE IIr.
A man, aged 50, developed a papulo-erosive chancre on the glans penis in 1891. He was treated with mercury for four months after infection, but had had no treatment since. When seen on September 20th, 1921, he stated that he had suffered from lightning pains in his legs for the last eighteen years, and from urinary incontinence for over five years. His physical signs were those typical of a case of tabes, and in addition he wore a portable urinal. An examination of cerebro-spinal fluid on September 20th, 1921, gave the following results: Cells 22, globulin test positive, Wassermann reaction strongly positive, gold sol 012441000 .

Treatment was at once instituted, and, although it is now only two montls since it was started, the patient's general condition two montlus since it was started, the patient's general condition
has already vastly improved. The lightning paius have entirely disappeared, and, although he still has some frequency of micturition, his bladder trouble is very much better, and he has given up his portable urinal. There is no alteration, however, in the cerebro-spinal fluid picture, and when this was examined on November 16th, 1921, it was practically the same as on September 20th. He still, of course, shows the same physical signs as before, but irom his point of view his life is now worth living, and he can pass water almost like a normal man instead of having to let it dribble into a urinal all day long.

Case IV.

A man, aged 46, developed a papulo-erosive chancre on the glans penis in 1901, and was treated with mercury for eighteen months. When seen on April 6th, 1921, he showed the usual physical signs of thoses plus a greatly enlarged Charcot's left knee-joint, which had appeared after a kick from a horse in France in 1917, and for which he wore a special walking apparatus. He complained of lightning pains and headache, and could not He complained of when they started His first course of treatment extended from when they started. His first course of treatment extended from
A pril 6th to June ist, 1921 . His cerebro-spinal fluid was examined on both of these dates, with the following results:

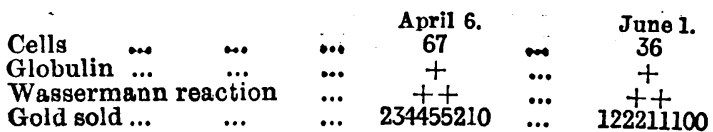

By this time the lightuing pains had greatly improved, but the most interesting thing of all was that the Charcot joint was now half its former size, the whole of the redundant synovial fluid having been absorbed. The expensive apparatus which he was wearing was now much too big for him, and he had to discard it. In August, 1921, he began to suffer from headaches again, so he was given a further course of treatment, which resulted in the disappearance of this symptom. At the present time he is free from symptoms, and the effusion in the Charcot's joint has recurred. His cerebro-spinal fluid picture is still much the same as when treatment was first started.

\section{Case v.}

A man, aged 36, developed a papulo erosive chancre on the coronal sulcus in 1911, and was treated in Italy for three and a half years with weekly intramuscular injections of mercury (with occasional rests) and potassium iodide by the mouth. He remsined perffetly well until the beginning of 1920. - At this time he began to neglect his work, and his friends and relatives noticed that ho was was getting slovenly and holiday by his firm with instructions to "pull himself together" On June 29th, 1920, he presented himself at hospital. He talked volubly with a markedly sturring speech, the tendon reflexes were exaggerated, and the pupils sluggish and irregular. It seemed obvious that he had developed general paralysis, and this opinion was confirmed by an examination of the cerebro-spinal fluid, which gave the following result: Cells 55, globulin and Wassermann ests both strougly positive, gold sol 55555554342

He was treated from June 29 th to August 10th, 1920, with the result that his mental condition considerably improved. He was given anothe: course in November and December, 1920, and it is worth noting that the pathological picture of his cerebro-spinal fluid on December 1st, 1920, was: Cells 50, globulin test positive, Wassermann reaction strongly positive, gold sol 55555544433 . By March, 1921, his general condition had improved so much
that he returned to his work. During 1921 he has received two courses of special trestment. His speech is still slurred, but his mental condition is good. He finds no trouble with his work, and appears rational and intelligent. The last examination of his cerebro-spinal fluid was on November $29 \mathrm{th}$, 1921, and the result was as follows: Cells 22, globulin and Wassermann tests both strongly positive, gold sol 55555555221 . One can therefore say that a considerable part of the symptom-complex of general paralysis of the insane has for the time being at any rate disappeared, although the cerebro-spinal fluid picture is still absolutely pathognomonio of that condition.

The cases were all under the care of Mr. McDonagh, and my thanks are due to him for his kindness in allowing me to make use of them, and for his unfailing help and resourceful. ness when difficulties were encountered. Without his co. operation the work could not have been done. Furthermore, I cannot conclude this survey without stating that I have merely carried on the work which was begun by the late $D r$. Lawrence Shaw, and which was cat short by his untimely death in March, 1921. To him, therefore, belongs much of the credit for the good results obtained. The pathological work was done by Mr. Victor Corbett, and to him also I express my thanks.

1 McDonagh : Venereal Diseases (1920), chapter xil. 2 Barbat: Journ. Amer. Med. (1918), ii, 15.

\section{THE TREATMEN'T AND PROGNOSIS OF LEPROSY.*}

BY

P. HARPER, M.R.C.S., L.R.C.P.,

MEDICAE SUPERINTENDENT, MAKOGAT LEPER ASYLUM, FIJI.

Or the general measures that can be taken for the benefit of lepers the following are essential:

(a) Regular meals of abundant food, including plenty of milk. Unfortunately I do not know what is the diet of the majority of patients at Makogai. I only know what the Government ration is, and that is certainly not the complete diet of the patients.

(b) A literally open-air life. At Makogai the wards, openair as they are, are used merely as dormitories, the patients spending practically all their time in the shade of trees, or in shelters or in their gardens.

(c) Gentle exercise and daily baths. The latter are very important from the ease with which lepers get small wounds. If the skin is clean there is not much harm from them, but if the skin is dirty they may form the starting point of very serious infection.

(d) Happiness of mind, obtained by kindly personal interest, plenty of amusement, and remunerative work. There should be as little petty discipline and interference as possible, and there should be no talk nor hint, whether by staff, patients, or visitors, of the loathsomeness or incurability of the disease.

Leprosy is not incurable, nor is it nearly as loathsome as many other diseases. But though we disapprove, we must still recognize and allow for the stigma that is attached to leprosy, a stigma due in part to the rareness of the disease in civilized countries with a corresponding ignorance on the part of the general public. This stigma will, of course, soon pass away, just as the horror with which sleeping sickness was regarded twenty years ago has disappeared with the increase of knowledge. One can have nothing but praise for the humane campaign of the Hawaiian leprologists for the true education of the public and the consequent eradication of this mediaeval stigma. Leprosy is a disease of such low infectivity that it appears to me to be the ideal disease for treatment at the patient's home. I do not agree that com. plete compulsory segregation will ever succeed in wiping the disease out of $\mathrm{Fiji}$, whereas segregation at home or in an

* A paper read at a meeting of the Fiji Branch of the British Medical Association. May, 1922 